\section{Whiplash: Nothing to Lose Sleep Over}

\section{To the Editor:}

Although Radanov, et $a l^{1}$ have recently suggested that sleep disturbance may be an important problem in chronic whiplash, we would argue that the etiology of chronic whiplash is nothing to lose sleep over, since we are coming to understand the individual factors that determine who develops chronic pain and who does not ${ }^{2}$. Radanov, et al have confirmed what has long been known: that the symptoms and/or pattern of symptoms of chronic whiplash are in fact not distinct. Indeed, it was shown as much as a decade ago that there is no distinct symptom pattern for chronic whiplash as assessed by the Symptom Checklist- $90-\mathrm{R}^{3}$, and this tool does not even distinguish between minor head injury and whiplash injury, which both show similar profiles ${ }^{4}$. This is not surprising, since it is now well known that the prognostic factors for recovery from a number of injury conditions are not dependent on the injury itself, but rather psychosocial factors. The Neck Pain Task Force was able to identify a number of specific risk factors for the condition referred to as chronic or "late whiplash" . Even more recently, the search for specific risk factors in the development of late whiplash has proven to be quite fruitful. We suggest that instead of focusing on the common symptoms in different pain conditions and matters such as sleep disturbance, we should continue to understand these prognostic factors in the development of the late whiplash syndrome.

The outcomes from whiplash injury and minor head injury have been shown, for example, to be chiefly determined by beliefs and coping styles $6,7,8,9,10,11,12$. Indeed, even the outcomes from nontraumatic neck and back pain are in large part determined by coping style ${ }^{12}$. Whether the spinal pain arises from injury or not, the tendency to hold passive strategies such as relying heavily on pain medications, frequently focusing on and discussing one's pain with others, and canceling social activities leads to a poor outcome ${ }^{6}$.

There is also a frequent expectation in Western countries that whiplash injury will lead to chronic pain ${ }^{8}$, a phenomenon that is not observed in countries where chronic whiplash is less prevalent ${ }^{13}$. A study has again shown that there is a robust association between expectations for recovery and actual recovery in patients with whiplash ${ }^{6}$. These findings have direct and important clinical interventions. Rather than focusing on what is likely a secondary and difficult-to-measure problem of sleep disturbance, researchers and clinicians can readily assess beliefs and coping style, and use them to predict those patients with a poor prognosis. Expectations for type, intensity, and duration of whiplash-associated symptoms exist prior to the injury. It seems likely that these prior beliefs are influential in the expectations individuals form for their own recovery after an actual injury, and that these expectations for recovery are modified by the immediate injury experience (for example, initial pain intensity and extent), as well as by early experiences with healthcare professionals. As we come to understand how these factors determine who develops chronic pain and who does not, we can develop a wide array of interventions, such as changes in legislative systems, insurance schemes, and therapeutic approaches that appear to interrupt the effects that beliefs, expectations, and coping style have on outcomes. Indeed, this approach will be helpful in a variety of conditions.

Understanding the illness beliefs held by the general population concerning motor vehicle collision injury, minor head injury, neck pain, and back pain, in general, and their expectations for recovery is proving to be a parsimonious approach. We all need to work harder to understand and treat these challenging syndromes.

ROBERT FERRARI, MD, MSc (Med), FRCPC, FACP; ANTHONY SCIENCE RUSSELL, MB, BChir, FRCPC, Department of Rheumatic Diseases, University of Alberta, Edmonton, Alberta, Canada. Address correspondence to Dr. R. Ferrari, University of Alberta Hospital, Department of Medicine, 13-103 Clinical Sciences Building 11350 - 83 Avenue, Edmonton, Alberta T6G 2P4, Canada. E-mail: rferrari@shaw.ca

\section{REFERENCES}

1. Radanov BP, Mannion AF, Ballinari P. Are symptoms of late whiplash specific? A comparison of SCL-90-R symptom profiles of patients with late whiplash and patients with chronic pain due to other types of trauma. J Rheumatol 2011;38:1086-94.

2. Ferrari R, Russell AS. Collisions and chronic pain: The solution is finding the problem. Comment on article by Jones et al. Arthritis Care Res 2011;63:1495-6.

3. Peebles JE, McWilliams LA, MacLennan R. A comparison of symptom checklist 90 -revised profiles from patients with chronic pain from whiplash and patients with other musculoskeletal injuries. Spine 2001;26:766-70.

4. Westcott MC, Alfano DP. The symptom checklist-90-revised and mild traumatic brain injury. Brain Inj 2005;19:1261-7.

5. Carroll LJ, Holm LW, Hogg-Johnson S, Cote P, Cassidy JP, Haldeman S, et al. Course and prognostic factors for neck pain in whiplash-associated disorders (WAD): Results of the Bone and Joint Decade 2000-2010 Task Force on Neck Pain and Its Associated Disorders. J Manipulative Physiol Ther 2009;32 (2 Suppl):S97-107.

6. Carroll LJ, Holm L, Ferrari R, Ozegovic D, Cassidy JD. Recovery in whiplash-associated disorders: Do you get what you expect? J Rheumatol 2009;36:1063-70.

7. Holm LW, Carroll LJ, Cassidy JD, Skillgate E, Ahlbom A. Expectations for recovery important in the prognosis of whiplash injuries. PLoS Med 2008;5:e105.

8. Bostick GP, Ferrari R, Carroll LJ, Russell AS, Buchbinder R, Krawciw D, et al. A population-based survey of beliefs about neck pain from whiplash injury, work-related neck pain, and work-related upper extremity pain. Eur J Pain 2009;13:300-4.

9. Whittaker R, Kemp S, House A. Illness perceptions and outcome in mild head injury: A longitudinal study. J Neurol Neurosurg Psychiatry 2007;78:644-6.

10. Wolters G, Stapert S, Brands I, Van Heugten C. Coping styles in relation to cognitive rehabilitation and quality of life after brain injury. Neuropsychol Rehabil 2010;20:587-600.

11. Carroll L, Cassidy JD, Cote P. The role of pain coping strategies in prognosis after whiplash injury: Passive coping predicts slowed recovery. Pain 2006;124:18-26.

12. Mercado AC, Carroll LJ, Cassidy JD, Côté P. Passive coping is a risk factor for disabling neck or low back pain. Pain 2005;117:51-7.

13. Ferrari R, Schrader H. The late whiplash syndrome. J Neurol Neurosurg Psychiatry 2001;71:821.

J Rheumatol 2012;39:3; doi:10.3899/jrheum.110970 